\title{
Desenvolvimento, sustentabilidade e ambiente na visão de professores de Ciências do município de Codajás- AM
}

\author{
Development, sustainability, and environment in the view of Science \\ teachers in the municipality of Codajás- AM
}

\author{
Raynara Sobrinho da Silva', Elizandra Rego de Vasconcelos"
}

\begin{abstract}
RESUMO
O ensino de ciências permite uma compreensão mais ampliada por meio das observações e análise das problemáticas locais que envolvem a realidade escolar (VASCONELOS, 2016). O objetivo deste estudo foi compreender relações entre temas socioambientais e o ensino de ciências escolar no sentido de alcançar o letramento científico. Para isto, usou-se o método exploratório descritivo (VERGARA, 2009; GIL, 2010) que favorece a aproximação com o objeto estudado e contempla a pesquisa empírica. Foram realizadas as seguintes atividades: 1) pesquisa bibliográfica; 3) entrevista semiestruturada com professores de ensino fundamental maior. O estudo das unidades empíricas e teóricas favoreceram uma análise textual discursiva com os contextos que o referencial teórico situa. As respostas dos professores foram analisadas e organizadas de acordo com as categorias citadas por Reigota (2010), são elas: naturalista, globalizante e antropocêntrica.
\end{abstract}

Palavras-chave: Socioambiental; Educação Ambiental; Ensino de Ciências.

\section{ABSTRACT}

Science teaching allows for a broader understanding through observations and analysis of local problems involving school reality (VASCONELOS, 2016). The aim of this study was to understand the relationship between socio-environmental themes and school science teaching in order to achieve scientific literacy. For this, the exploratory descriptive method (VERGARA, 2009; GIL, 2010) was used, which favors the approximation with the object studied and includes empirical research. The following activities were carried out: 1) bibliographic research; 3) semi-structured interview with teachers of higher education. The study of empirical and theoretical units favored a discursive textual analysis with the contexts that the theoretical framework situates. The teachers' responses were analyzed and organized according to the categories mentioned by Reigota (2010), they are: naturalist, globalizing and anthropocentric.

Keywords: Socioenvironmental; Environmental Education; Science Teaching.

I Graduação em andamento em Ciências Naturais, UFAM. E-mail: raynarasobrinho.sds@gmail.com. ORCID: https://orcid.org/0000-0001-9193-0681.

"Doutora em Educação Científica e Tecnológica. Coordenadora do Curso de Licenciatura em Ciências Biológicas, UFAM. E-mail: elizandravasconcelos@hotmail.com. ORCID: https://orcid.org/0000-0002-9634-4523. 


\title{
1 INTRODUÇÃO
}

O desenvolvimento de atividades educacionais ambientais relacionadas ao ensino de ciência possibilita ao sujeito a participação na conservação do meio onde se vive. Isto possibilita a colaboração para uma sociedade local, que promove a capacidade de compreender e analisar possíveis problemas sociais em sua comunidade. E assim contribuir para a sustentabilidade do planeta à medida que tais assuntos forem abordados no contexto escolar.

Questão socioambiental um debate a ser discutido no âmbito educacional, em grupos de sociedade e suas emergências, Carvalho (2006, p. 23-24) diz:

\begin{abstract}
O surgimento da questão ambiental como um problema que afeta o destino da humanidade tem mobilizado governos e sociedade civil. Nas últimas décadas, todo um conjunto de práticas sociais voltadas para o meio ambiente se tem instituído tanto no âmbito das legislações e dos programas de governo quanto nas diversas iniciativas de grupos, de associações e de movimentos ecológicos. Na esfera educativa temos assistido à formação de um consenso sobre a necessidade de problematização dessa questão em todos os níveis de ensino. Assim, a EA vem sendo valorizada como uma ação educativa que deveria estar presente, de forma transversal e interdisciplinar, articulando o conjunto de saberes, formações de atitudes e sensibilidade ambientais.
\end{abstract}

Os temas socioambientais são relevantes, pois na medida em que a relação entre homem-natureza possibilita a forma do ser humano conviver e operar em conjunto na sociedade dando destaque ao cuidado do meio ambiente, de tal modo, a sociedade passa por uma transição de bastante crise ambiental devido aos fortes fenômenos naturais que ocorre no mundo como: tsunami, rios poluídos, corpos hidráulicos extintos, quer sejam por represas, quer por empresas marítimas que jogam seus detritos tóxicos nos mesmos, desmatamento, queimadas, todos esses fatores vão se agravando e causando uma degradação ambiental forte ao meio ambiente devido a sociedade não se impor a este problemas ambientais.

Karl Marx (1985), Cita: 
[...] a existência [...] de cada elemento da riqueza material não existente na natureza, sempre teve de ser mediada por uma atividade especial produtiva, adequada a seu fim, que assimila específicas. Como criador de valores de uso, como trabalho útil, é o trabalho, por isso, uma condição de existência do homem, independente de todas as formas de sociedade, eterna necessidade natural de mediação do metabolismo entre homem e natureza e, portanto, da vida humana. (MARX, 1985a, p.50)

Assim, associava-se homem a natureza e o trabalho, pois estão relacionadas em conjuntos elementares inseparáveis, ou seja, o homem transforma a natureza em busca de suas necessidades fundamentais para a sua existência, mas esse trabalho deverá ser constituído com uma relação de uma troca, o homem devolve para a natureza o que obteve para o seu benefício em forma de replantio ou como o cuidado do meio em que vive, porém, se a execução for positiva, teremos uma sustentabilidade, por outro lado, se não atuar de forma positiva teremos a degradação ambiental, a destruição do meio ambiente. Não obstante, construindo problemas socioambientais adquiridos pela a natureza humana de sua forma de sobrevivência.

Por exemplo, as hidrelétricas quando são construídas causam nas regiões atingidas, vários alagamentos, algumas mortes de animais ao redor, moradores são obrigados a sair de suas casas devido a construção das hidrelétricas. Na Amazônia, Carvalho diz (2009, p. 49);

O perfil socioambiental que vem se desenhando na Amazônia é - de restoResultado, pensamos, de um processo de europeização e ocidentalização da cultura desse recanto do mundo que se encontra entrelaçadas como culturas autóctones predominando, porém, sobre estas.

A Amazônia é rica de diversidades, e possui diversificações biológicas, e culturais. Podemos comentar a representatividade das grandes nascentes de rios da região, porém, a uma degradação destes rios, muita poluição, tornando inutilizado para os moradores do local, temos os parque de Manaus, como o INPA-bosque da ciência, Parque do Mindu e bilhares, esses dois parque encontra-se como uma degradação ambiental, pois, seus rios que poderia serem usados como atração estão 
poluído e os desmatamentos em áreas indígenas, segunda a pesquisa (INEP, 2017) esse fator agravou-se 32\% em terras indígenas. A relação antrópica na comunidade tem desenvolvido diversos problemas, tais como: desmatamento, mau uso das fontes hídricas, crescimento de doenças endêmicas etc. Somado a isto, a carência na saúde, educação precária, aumento da desigualdade dentre outros. Isto revela o contraste entre a rica Amazônia com a realidade vivenciada pelos amazônicas. Essa discussão pode ser tratada nas salas de aulas, a partir de atividades diferenciadas no ensino de ciências. Sobre isto:

A dinâmica da construção do conhecimento científico tem sido alicerçada em diversas formas de aprendizado, que se utilizam da pesquisa, e do desenvolvimento tecnológico como ferramenta, em parte "emprestado" de uma ciência a outra. Neste contexto, existem duas tendências atuais da ciência moderna: a especialização e a interdisciplinaridade. A primeira mais relacionada a ciência da natureza, de caráter mais "formal" e a segunda mais relacionada a ciência humana e a sociais, de caráter "factual" (RIVAS, 2014, p.25).

O ensino de ciências, quando associado à dimensão socioambiental da comunidade, permite uma compreensão mais ampliada por meio das observações e análise dos problemas socioambientais envolvem a realidade escolar e visando o lado sustentável do contexto. Sendo assim, o ensino de ciência ajuda a compreender alguns questionamentos do ser humano, como a origem de tudo, reprodução, evolução da vida, hábitos alimentares, e ambientais auxiliando na conscientização da sociedade, e questões relacionada à saúde, sendo assim, a ciência é uma área extensa, que obtém informações aos alunos e suas curiosidades, tendo um papel fundamental na vida do ser humano, tornado uma área de grandes responsabilidades ao ser lecionada, ou seja, o ensino de ciência busca solucionar problemas incluindo a realidade do aluno e suas dificuldade, sempre visando a importância do entendimento dos conceitos ensinado sobre a tudo a tudo que Ihe cerca, a existência de determinado assunto ou fenômeno. 
A discussão deste assunto nas aulas ciências remete as relações entre ciências tecnologia sociedade (CTS). Na educação básica, a finalidade central no enfoque CTS é contribuir para tomadas de decisões responsáveis sobre questões de Ciência e Tecnologia, para que adquiram um olhar crítico sobre o papel da ciência e da tecnologia na sociedade, uma vez que este enfoque seja ampliado para discussões em sala de aula acerca de questões políticas, econômicas, culturais, sociais, ambientais e éticas (SANTOS; MORTIMER, 2002). A evolução dos conhecimentos científicos e tecnológicos tem gerado transformações na sociedade e na econômica, e consequentemente provocam discussões sobre possíveis problemas que caracterizam-se em crise ambientais, que poderiam serem realizados em forma de debates na educação básica juntamente com os alunos, para assim, conceber uma compreensão melhor sobre os fatores que emergiriam essas crises ambientais na sociedade.

As problemáticas ambientais e as crises decorrentes dos processos da evolução humana podem ser transformadas por meio de uma visão reflexiva sobre uma educação para o desenvolvimento sustentável (EDS) no âmbito escolar. Desse modo, os indivíduos sociais poderão tomar decisões para a busca da sustentabilidade. Salientando a forma que é desenvolvida o conteúdo, na disciplina de ciências e a tecnologia, pelos os professores em sala de aula, diante das temáticas: socioambiental, sustentabilidade e desenvolvimento.

Os professores buscam formas de desenvolverem os conteúdos sobre os temas ambientais e sustentabilidade, por meio de projetos educacionais ambientais, ações pedagógicas, palestras que podem ser realizadas com interdisciplinaridade em conjuntos com outras disciplinas para alcançar a conscientização ambiental de seus alunos e uma visão mais crítica. Entretanto, antes de saber como fazer tal intervenção questiona-se como o docente tem compreendido as relações entre temas socioambientais e o ensino de ciências escolar? Está questão moveu a pesquisa. 


\section{PROCEDIMENTOS METODOLÓGICOS}

A análise deu-se inicialmente por uma pesquisa bibliográfica sobre a temática, na qual desenvolveu por meio de leitura de livros e artigos, resenhas críticas e resumos para o melhor entendimento sobre os temas socioambientais. O referencial teórico utilizado para analisar o corpus da pesquisa foi o livro 'Meio Ambiente e Representação social' de Reigota (2010), na qual obteve uma importância extrema para o andamento da pesquisa.

Durante o planejamento experimental/ estudo. Optou-se por uma pesquisa exploratória e descritiva, como bem nos assegura GIL (2002, pág. 41-42)

[...] pode- se dizer que a pesquisa exploratória é baseada em fontes literários e elaborações de questionários/entrevista com o público alvo através de sua experiência e a problemática da pesquisa, ou seja, a sua busca é aprofundada a procurar conteúdo importante ao tema dentro do contexto da pesquisa. E o mais inquietante, todavia, é constar que a classificação descritiva tem como objetivo descrever características de um determinado público.

A pesquisa foi realizada no Município de Codajás-AM, localizada no interior do Estado do Amazonas respectivo a uma região geográfica intermediária de Manaus, com estimativa de 28 mil habitantes dados coletados pelo IBGE, com uma Área de 18. 712 km². Sua principal atividade econômica são os turismos, o açaí como é bastante conhecida o município "a terra do açaí" e também atividade pesqueira.

\section{Figura 1- localização geográfica de Codajás}

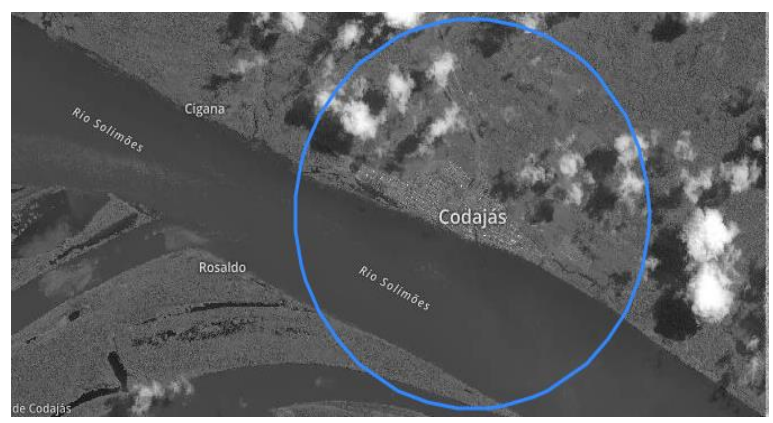

Fonte: Mapa de Satélite da Codajás. 
O Desenvolvimento da coleta dos dados da pesquisa, deu-se por meio de questionário composto por três questões submetidas aos professores de ciências que atuam no ensino fundamental menor e maior, com faixa etária entre vinte e quatro (24) a cinquenta anos (50) sobre a visão deles em relação aos seguintes conceitos: Ambiental, meio ambiente e desenvolvimento sustentável.

Com a intenção de compreender a temática em relação com o ensino de ciências, através das respostas dos participantes, analisamos minuciosamente suas ideias sobre as questões apresentadas no contexto local. Durante a análise das respostas obtidas por meio dos questionários, aplicou-se a técnica denominada ATDAnálise Textual Discursiva, no qual foram desenvolvidas por etapas que são essas:

\section{Figura 2 -Modelo de ATD - Análise Textual dissertativo}

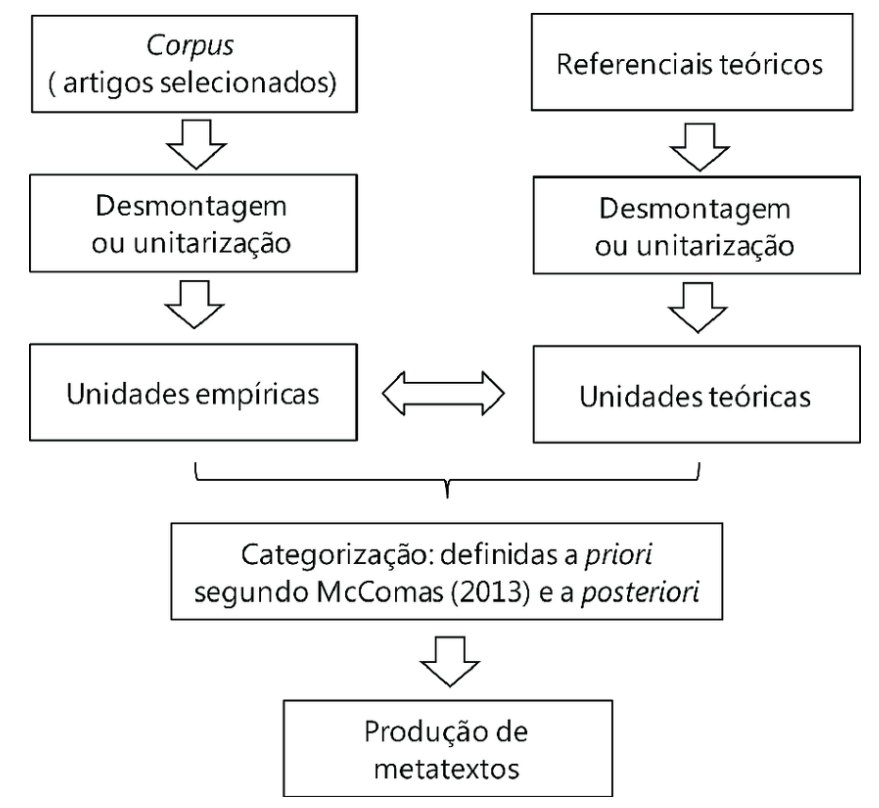

Fonte: Callegario, Rodrigues Junior, Luna \& Malaquias (2017).

I. Unitarização que consiste na leitura aprofundada e detalhada dos dados, na qual, analisamos parte a parte da produção dos textos dos participantes, para assim selecionar parte principal e que fazem sentindo, denominada de: Unicidade de sentindo. As respostas dos entrevistados dos questionários em 
conjuntos da literatura da obra de Reigota (2010) lida, compõem o corpus da pesquisa e referencias teóricos. Com base nessas informações do corpus, podemos adquirir as unidades empíricas de análise, através do corpus e o livro contém portando uns referenciais teóricos que fundamenta a pesquisa, constituindo então a unidade teórica. alguns registro central da ideia dos participantes foram: "políticas públicas, sustentabilidade, conscientização, preservação da natureza", ou seja, unir toda a unidade de sentindo da produção dos participante entre essas, recortei a que fazia sentindo, em uma única unidade todas as ideias, para assim iniciar a segunda etapa.

II. Categorização que consiste em "processo de comparação constante entre as unidades definidas no processo inicial de análise, levando ao agrupamento de elementos semelhantes (MORAES, 2003, p. 197)". Nessa etapa, a unidades empíricas e a teórica estão sempre relacionadas. A categorizei as unidades de sentindo dos participantes em: Globalizante, Naturalista e por fim antropocêntrica com Problemas. Portando, para a finalização do ATD organizei em uma tabela para melhor visualização de suas ideias centrais em relação a autor de comparação assim pude analisar o conceito que os professores deduziam com os temas das questões com a definição que o autor descreve em seu livro.

III. A produção do Metatextos são a realização da produção de "textos descritivos e interpretativos a partir das unidades de significado e das categorias" (MORAES; GALIAZZI, 2011, p. 40). Em que os textos analisados podem-se ser compreendidos, sendo relacionado através da unidade empíricas e teóricas. 


\section{RESULTADOS E DISCUSSÕES}

A pesquisa iniciou por meio de um levantamento bibliográfico a partir de diversas literaturas nacionais sobre o temas socioambientais e ensino de Ciências, além do mais busca eletrônica de artigos sobre os temas relacionadas a proposta do artigo tais são: Scielo, google scholar, Teses, revistas, e sites, nas quais foram realizados uma leitura prévia dos resumos e assim verificamos e estudamos. A pesquisa utilizouse as seguintes Palavras-Chaves: Problemas socioambientais, Educação Ambientais, Ensino de Ciências, ATD- análise Textuais Dissertativas, Ciências e Tecnologias. As respostas dos entrevistados foram organizadas conforme a ATD.

Esta literatura foi usada para analisar o material coletado durante as entrevistas semiestruturadas mediadas por questionário. A questão proposta aos professores, sujeitos da pesquisa, foi a seguinte: De acordo com seu conhecimento fale sobre os seguintes conceitos: ambiental, meio ambiente e desenvolvimento sustentável.

\section{Tabela 1 - Tabulação dos questionários (corpus da pesquisa)}

\begin{tabular}{|c|c|c|c|}
\hline Sujeito & Ambiental & Meio Ambiente & Desenvolvimento sustentável \\
\hline P1 & $\begin{array}{l}\text { "A educação Ambiental, se reflete } \\
\text { a tudo que na cerca, pois, } \\
\text { dependemos, diariamente do } \\
\text { ambiente que nos rodeia. A sua } \\
\text { diferença é que na educação } \\
\text { ambiental aprendemos relações } \\
\text { referentes ao meio ambiente" }\end{array}$ & $\begin{array}{l}\text { "É tudo que nos } \\
\text { rodeia, na cerca e } \\
\text { precisamos } \\
\text { diariamente dele." }\end{array}$ & Não respondeu \\
\hline P2 & “Cuidar e respeitar a natureza” & “"́ a vida na natureza. & $\begin{array}{l}\text { "É a transformar a partir de } \\
\text { atitude política a ética, e } \\
\text { sociedade" }\end{array}$ \\
\hline P3 & $\begin{array}{l}\text { "Refere-se ao ambiente no qual } \\
\text { se vive" }\end{array}$ & $\begin{array}{l}\text { "É o conjunto de } \\
\text { vários fatores que } \\
\text { formam o meio" }\end{array}$ & $\begin{array}{l}\text { "Refere-se à preservação dos } \\
\text { recursos naturais para que as } \\
\text { gerações futuras possam } \\
\text { conhecer e usufruir desses } \\
\text { recursos." }\end{array}$ \\
\hline
\end{tabular}


Desenvolvimento, sustentabilidade e ambiente na visão de professores de Ciências do município de... |

\begin{tabular}{|c|c|c|c|}
\hline Sujeito & Ambiental & Meio Ambiente & Desenvolvimento sustentável \\
\hline P4 & Não respondeu & $\begin{array}{l}\text { "Com os seres vivo } \\
\text { que tem vida e a } \\
\text { floresta e os animais" }\end{array}$ & $\begin{array}{l}\text { "É o transformar a realidade e a } \\
\text { partir de atitude em busca de } \\
\text { compreender a realidade" }\end{array}$ \\
\hline P5 & "conscientização da população" & $\begin{array}{l}\text { "desmatamento da } \\
\text { nossa floresta" }\end{array}$ & $\begin{array}{l}\text { "É o desenvolvimento que procura } \\
\text { satisfazer as necessidades da } \\
\text { geração atual, sem comprometer } \\
\text { a capacidade das gerações } \\
\text { futuras de satisfazerem a suas } \\
\text { próprias necessidades" }\end{array}$ \\
\hline P6 & Não respondeu & $\begin{array}{l}\text { "Meio onde } \\
\text { moramos e ambiente } \\
\text { escolar." }\end{array}$ & $\begin{array}{l}\text { "É ordem, progresso, ou seja, tudo } \\
\text { que é sustentável. Proteção } \\
\text { ecológica, trabalho, política e } \\
\text { respeito, conscientização." }\end{array}$ \\
\hline \multirow[t]{2}{*}{ P7 } & Não respondeu & Não respondeu & $\begin{array}{l}\text { “Ocorre quando um projeto, é } \\
\text { executado na prática e, da certa, } \\
\text { como por exemplo: }\end{array}$ \\
\hline & & & A criação de peixe tambaqui" \\
\hline P8 & $\begin{array}{l}\text { Senso de humor a educação, } \\
\text { exemplo de humanidade." }\end{array}$ & "É natureza" & $\begin{array}{l}\text { "É a compreensão da situação, } \\
\text { onde podemos contribuir com a } \\
\text { transformação da natureza e o } \\
\text { ambiente." }\end{array}$ \\
\hline P9 & $\begin{array}{l}\text { "É tudo que nos cerca na } \\
\text { natureza, no lugar onde vivemos } \\
\text { juntos com os animais e } \\
\text { vegetais." }\end{array}$ & $\begin{array}{l}\text { "É o local onde } \\
\text { estamos na casa, } \\
\text { escolar e rua etc." }\end{array}$ & $\begin{array}{l}\text { "É o progresso do } \\
\text { desenvolvimento ambiente na } \\
\text { natureza cada aspecto surgir" }\end{array}$ \\
\hline P10 & $\begin{array}{l}\text { "É tudo o que está no meu redor, } \\
\text { próximo a mim, o que eu vejo, } \\
\text { pego e cuido para preservar os } \\
\text { seres vivos, vegetais para a sua } \\
\text { existência nesse planeta." }\end{array}$ & $\begin{array}{l}\text { "É tudo o que está no } \\
\text { meu meio, em casa, } \\
\text { trabalho, cidade." }\end{array}$ & $\begin{array}{l}\text { "É o progresso que compreende a } \\
\text { necessidade das pessoas, } \\
\text { transformando a sua realidade } \\
\text { local a partir de suas atitudes, de } \\
\text { uma forma consciente de } \\
\text { observar a natureza de um lado e } \\
\text { a humanidade de outro." }\end{array}$ \\
\hline P11 & $\begin{array}{l}\text { "preservar a natureza, } \\
\text { sustentabilidade e lixo" }\end{array}$ & “Conscientização” & $\begin{array}{l}\text { "É a importância para o meio } \\
\text { ambiente, obter o crescimento } \\
\text { sustentável, econômico } \\
\text { necessário preservação do meio } \\
\text { ambiente." }\end{array}$ \\
\hline
\end{tabular}


A forma adotada para analisa o corpus da pesquisa, deu-se por meio da tabulação das respostas dos professores no word, em forma de tabela. No fim da tabulação, colocamos em prática a unitarização de sentindo das palavras significativas para o contexto da pesquisa encontradas no corpus, material selecionado de acordo a literatura de base.

A partir deste processo de análise, identificamos falas, expressões e frases que se alinhavam com as três categorias a priori reveladas por Reigota (2010) que estão apresentadas na tabela 2.

\section{Tabela 2 - Representação da Tipologia de Priori de Reigota (2010)}

\begin{tabular}{ll}
\hline Categoria & \multicolumn{1}{c}{ Unidade de significado } \\
\hline Globalizante & entre sociedade e a natureza em relação ao contexto geral, seja ele, \\
& entre a sociedade e natureza. \\
Naturalista & O homem como observador da natureza, um contexto como uma \\
& natureza intocável \\
Antropocentrica & Utilização dos recursos naturais, para suprir as necessidades da \\
& sociedade \\
\hline
\end{tabular}

A categorização das unidades de significado, deu-se por meio, da unidade teórica do livro de Reigota (2010), na qual se diz "Reações reciprocas entre natureza e sociedade". No sentindo da categoria Globalizante, já o naturalista, analisa como o homem apenas sendo um observador no contexto ambiental, e no antropocêntrica podemos notar a utilização da natureza como uma forma de gerar recursos de vida a sociedade Reigota (2010). Essa tipologia, podem ser melhor observadas na tabela 3, construída a partir das respostas dos professores. 
Desenvolvimento, sustentabilidade e ambiente na visão de professores de Ciências do município de... |

Tabela 3 - Tipologia com a concepção dos professores entrevistados segundo Reigota (2010)

\begin{tabular}{|c|c|c|c|}
\hline $\begin{array}{l}\text { Categoria/Sujeito da } \\
\text { pesquisa }\end{array}$ & Naturalista & Globalizante & Antropocêntrico \\
\hline $\mathrm{P} 1$ & $\begin{array}{l}\text { Ambiente que nos } \\
\text { rodeia. }\end{array}$ & $\begin{array}{l}\text { Atitude política a ética, e } \\
\text { sociedade. }\end{array}$ & $\begin{array}{c}\text { Preservação dos } \\
\text { recursos naturais para } \\
\text { que as gerações futuras. }\end{array}$ \\
\hline P2 & $\begin{array}{c}\text { “Cuidar e respeitar a } \\
\text { natureza." }\end{array}$ & $\begin{array}{l}\text { Local onde estamos na } \\
\text { casa, escolar e rua. }\end{array}$ & Humanidade. \\
\hline P3 & $\begin{array}{c}\text { "Ao ambiente no qual se } \\
\text { vive". }\end{array}$ & $\begin{array}{l}\text { Onde moramos e } \\
\text { ambiente escolar. }\end{array}$ & Conscientização. \\
\hline P4 & $\begin{array}{l}\text { Floresta e os animais e } \\
\text { seres vivos. }\end{array}$ & $\begin{array}{l}\text { É tudo o que está no } \\
\text { meu meio, em casa, } \\
\text { trabalho, cidade. }\end{array}$ & $\begin{array}{c}\text { Transformação da } \\
\text { natureza e o ambiente. }\end{array}$ \\
\hline P5 & $\begin{array}{c}\text { É o conjunto de vários } \\
\text { fatores que forma o } \\
\text { meio. }\end{array}$ & $\begin{array}{c}\text { Proteção; } \\
\text { Ecológica, trabalho, } \\
\text { política e respeito, } \\
\text { conscientização. }\end{array}$ & $\begin{array}{l}\text { Satisfazerem as suas } \\
\text { próprias necessidades. }\end{array}$ \\
\hline P6 & Natureza. & $\begin{array}{l}\text { Conscientização da } \\
\text { população. }\end{array}$ & $\begin{array}{l}\text { Desmatamento da nossa } \\
\text { floresta. }\end{array}$ \\
\hline P7 & $\begin{array}{c}\text { Observar a natureza de } \\
\text { um lado e a humanidade } \\
\text { de outro. }\end{array}$ & $\begin{array}{c}\text { Obter o crescimento } \\
\text { sustentável, econômico. }\end{array}$ & $\begin{array}{c}\text { Cuido para preservar os } \\
\text { seres vivos, vegetais para } \\
\text { a sua existência nesse } \\
\text { planeta. }\end{array}$ \\
\hline P8 & É natureza. & Não respondeu. & Não respondeu. \\
\hline P9 & $\begin{array}{c}\text { É tudo que nos cerca na } \\
\text { natureza. }\end{array}$ & Não respondeu. & Não respondeu. \\
\hline P10 & $\begin{array}{l}\text { É tudo o que está no } \\
\text { meu redor, os vegetais, } \\
\text { preservar os seres vivos. }\end{array}$ & Não respondeu. & Não respondeu. \\
\hline P11 & Preservar a natureza. & Não respondeu. & Não respondeu. \\
\hline
\end{tabular}

Nota-se que as categorias explicitadas por Reigota (2010) se fazem presentes no imaginário dos professores que atuam no Amazonas. A respostas mostram, que a compreensão dos professores sobre os conceitos de ambiental, meio ambiente e desenvolvimento sustentável compreendem as três categorias, não sendo encontradas por eles, os professores, diferenças entre uma e outra. Chama atenção 
a superioridade da categoria naturalista expressão por palavras como: natureza, preservação, floresta expressas principalmente por P2, P4, P6, P7, P10. Ideias já bastante criticadas no âmbito da literatura atual acerca da educação ambiental (LOUREIRO, LAYARGUES, CASTRO, 2014) destaca que o pensamento naturalista está mais próximo do senso comum quando comparado a complexidade do vínculo entre a questão ambiental e social.

No tocante a categoria globalizante, somente sete professores apresentam elementos que indicam compreensão mais ampla acerca da questão ambiental. Em especial P1, P5, P7 citam atitude política a ética, conscientização e crescimento econômico sustentável em suas respostas. Essas palavras ganham significado a partir da compreensão de uma educação ambiental que visa o compromisso social e o reestabelecimento das relações de justiça ambiental, desigualdade e transformação Social (LOUREIRO, LAYARGUES, CASTRO, 2009).

Quanto à categoria antropocêntrica, P1, P2, P4 E P5 destacam a preservação dos recursos naturais, transformação da natureza pela humanidade sinaliza para o caráter central das influências antrópicas sobre a natureza. O que revela um olhar muito mais de dominação do que de uso sustentável.

\section{CONSIDERAÇÕES FINAIS}

Após analisarmos os dados apresentados pelo o estudo, percebemos que a visão dos entrevistados ainda precisa ser aprofundada em relação aos conceitos: meio ambiente, ambiental e desenvolvimento sustentável e social. Para realizar um ensino de ciências que discuta a complexidade ambiental, os docentes precisam ver o contexto geral dos problemas socioambientais em suas aulas e que possam passar de formas mais aprofundadas em fundamentos teóricos.

Diante disso faz-se necessário uma ação conjunta em busca de desenvolver responsabilidade socioambiental que seja trabalhada nas escolas. 


\section{AGRADECIMENTOS}

Agradecimentos ao CNPQ pela bolsa de Iniciação Científica concedida.

\section{REFERÊNCIAS}

CARVALHO, Luiz. AMAZÔNIA - Espectros de globalização. Manaus/AM. Editora da Universidade Federal do Amazonas, 2009. Pág 49.

CARVALHO, I. C. M. Educação Ambiental: a formação do sujeito ecológico. São Paulo: Cortez, 2006.

GIL, antonio. Como elaborar projetos de pesquisa. 4 Ed. São Paulo: Atlas, 2002. Disponível em: https://www.socioambiental.org/pt-br/noticias-socioambientais/desmatamentocresce32-nas-terras-indigenas-da-amazonia-brasileira-aponta-isa. Acesso em: 10 de abril de 2019

INSTITUTO SOCIOAMBIENTAL. desmatamento cresce 32\% nas Terras Indígenas da Amazônia brasileira, aponta ISA. Manaus/AM: 2017.

LOUREIRO, F. LAYARGUES, P; CASTRO. R. S. Repensar a Educação Ambiental: um olhar crítico.

MARX, Karl. O Capital: crítica da economia política. São Paulo: Abril Cultural, 1985a. v.1.(Os economistas).

MORAES, R. Uma tempestade de luz: a compreensão possibilitada pela análise textual discursiva. Ciência \& Educação, v.9, n. 2, p.191-211, 2003.

Moraes, R. \& Galiazzi, M. (2011). Análise Textual Discursiva. 2.ed. Ijuí, RS: Unijuí REIGOTA, Marcos. Meio Ambiente e Representação Social. 8ed. São Paulo: Cortez, 2010.

RIVAS, Alexandre. Economia de serviços ambientais utilizando técnicas de preferências declaradas. Manaus/AM. Editora da Universidade Federal do Amazonas, 2014. Pág. 25.

SANTOS, W. L. P. dos; MORTIMER, E. F. Uma análise de pressupostos teóricos da abordagem C-TS (Ciência - Tecnologia - Sociedade) no contexto da educação brasileira. Ensaio Pesquisa em Educação em Ciências, v. 2, n. 2, p. 1-24, 2002. Disponível em: Acesso em: 10 de abril de 2019. 
VASCONCELOS, E. R. Questões socioambientais amazônicas, CTS e o ensino de ciências. Rev. Eletrônica Mestr. Educ. Ambient. v. 33, n.3, p. 161-177, set./dez., 2016. VERGARA, S. C. Projetos e relatórios de pesquisa em administração. São Paulo: Atlas. 2009. 